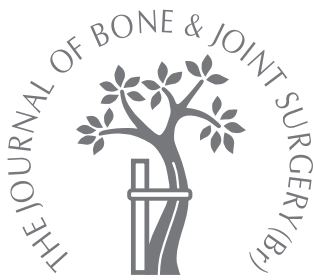

P. N. Baker, J. H. van der Meulen, J. Lewsey, P. J. Gregg

From James Cook University Hospital, Middlesborough, England

\title{
The role of pain and function in determining patient satisfaction after total knee replacement
}

\author{
DATA FROM THE NATIONAL JOINT REGISTRY FOR ENGLAND \\ AND WALES
}

\begin{abstract}
A postal questionnaire was sent to 10000 patients more than one year after their total knee replacement (TKR). They were assessed using the Oxford knee score and were asked whether they were satisfied, unsure or unsatisfied with their TKR. The response rate was $87.4 \%$ ( 8231 of 9417 eligible questionnaires) and a total of $81.8 \%$ (6625 of 8095 ) of patients were satisfied. Multivariable regression modelling showed that patients with higher scores relating to the pain and function elements of the Oxford knee score had a lower level of satisfaction ( $p<0.001$ ), and that ongoing pain was a stronger predictor of this. Female gender and a primary diagnosis of osteoarthritis were found to be predictors of lower levels of patient satisfaction. Differences in the rate of satisfaction were also observed in relation to age, the American Society of Anesthesiologists grade and the type of prosthesis.

This study has provided data on the Oxford knee score and the expected levels of satisfaction at one year after TKR. The results should act as a benchmark of practice in the United Kingdom and provide a baseline for peer comparison between institutions.
\end{abstract}

Traditionally, the evaluation of total hip (THR) or total knee replacements (TKR) has focused on the surgical and technical aspects of the procedure, assessed by the surgeon or derived from radiological studies, with complications such as failure of the prosthesis and alignment of the implant being used as end-points to assess outcome.

More recently, it has been shown that the views of surgeons and their patients on the outcome of medical and surgical interventions do not always agree, especially with respect to the assessment of function and pain. ${ }^{1,2}$ Likewise the concerns and priorities of patients and surgeons relating to joint replacement differ. ${ }^{3}$ For these reasons there is a growing recognition that evaluation should use patient-reported outcome tools and assessments of satisfaction. These ensure that the patient's perception of outcome is included in the evaluation of THR and TKR. ${ }^{4}$

Previous reports have described levels of satisfaction after primary TKR ranging between $81 \%$ and $89 \% .^{5-8}$ While these have highlighted some factors which have an influence on satisfaction, our current understanding of why some patients are satisfied and others are not remains limited.

The National Joint Registry for England and Wales ${ }^{9}$ found that $82 \%$ of patients were satisfied at just over one year after primary TKR.
Using the same data, we investigated why almost $20 \%$ of patients were not satisfied. Using the Oxford knee score ${ }^{10}$ and details held on the joint registry database, we aimed to investigate the relationship between these factors and patient satisfaction. In particular, we explored the relative influence of ongoing pain and functional limitation on satisfaction.

We hypothesised that pain would be a stronger determinant of satisfaction than function, for a number of reasons. First, pain is usually the primary indication for joint replacement. Secondly, patients have been shown to have higher expectations of relief from pain when compared with improvements in functional ability after TKR. ${ }^{11-13}$ Thirdly, it is relatively easy for patients to modify their level of activity, change their behaviour and adapt their environment so that functional deficiencies are overcome. By contrast, pain is less amenable to changes in lifestyle and behaviour and often remains a cause of considerable distress.

\section{Patients and Methods}

Since April 2003 the National Joint Registry has been collecting information on THRs and TKRs performed in England and Wales. By the end of July 2005 the mean weekly submission of completed records had reached 2400 operations, with $99 \%$ of all hospitals on the joint 
Table I. Breakdown of the Oxford knee score ${ }^{10}$

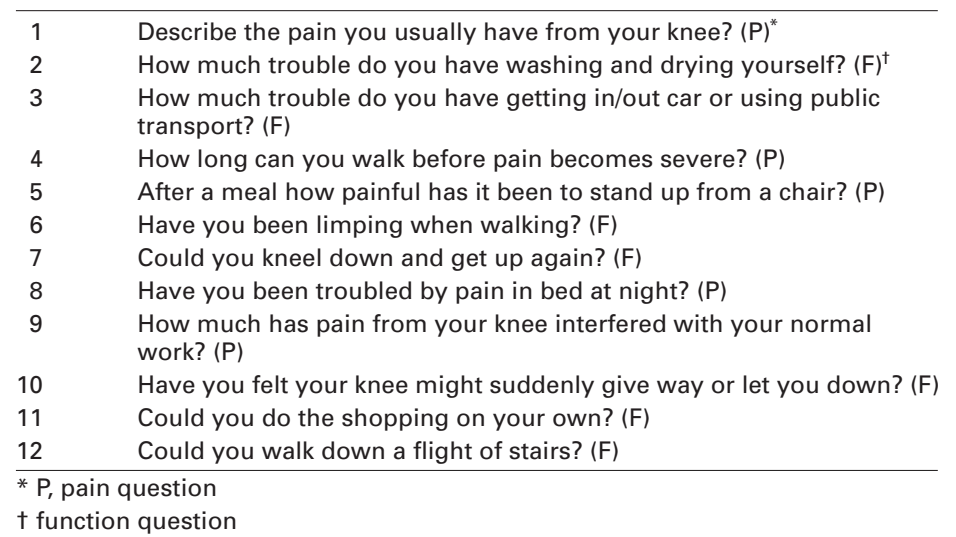

registry database submitting data. ${ }^{9}$ The proportion of all relevant joint replacements performed in England and Wales which was included in the joint registry database was approximately $60 \%$, and this proportion was similar for hospitals in the NHS and in the independent sector.

The National Joint Registry collects information about a large number of patient and surgical characteristics. For the purpose of this paper, we considered age in years, gender, hospital type (NHS, independent), type of prosthesis (cemented, uncemented, hybrid, unicondylar, patellofemoral), American Society of Anesthesiologists (ASA) grade ${ }^{14}$ (1, fit and healthy; 2 , mild disease; 3 , incapacitating disease; and 4 , life-threatening disease), operative side, grade of lead surgeon (consultant, associate specialist/staff grade/clinical assistant, SPR/SHO), indication for operation (osteoarthritis (OA), other diagnoses), type of incision (lateral, medial, midline), use of tourniquet and removal of the fat pad (fully, partially, not removed).

In March 2005, the National Joint Registry sent a postal survey to 10000 patients operated on between April and December 2003. These were randomly selected from all patients who had undergone a primary unilateral TKR, whose contact details had been recorded and who were alive in March 2005 according to the NHS strategic tracing service. The questionnaires contained the Oxford knee score, questions asking whether patients had experienced problems in addition to those addressed in the Oxford knee score, and a question relating to satisfaction with the outcome of their surgery.

The Oxford knee score is a patient-administered questionnaire which explores a subjective assessment of their pain and functional capacity. It is administered as a 12-part questionnaire, with five questions relating to the measurement of pain, and seven to the assessment of function. The answer to each question is rated on a scale ranging between 1 and 5, with higher scores indicating more severe problems. The scores for each question are added to generate an overall score of between 12 and $60 .{ }^{10}$

The Oxford knee score was chosen because it is a reliable, valid and responsive outcome measurement. ${ }^{15}$ It is simple, easy to administer and suitable for following up patients in the long term. It has been recommended as an appropriate disease-specific tool for assessing outcomes after $\mathrm{TKR}^{16}$ and is also preferred to the Western Ontario McMasters Osteoarthritis index (WOMAC) ${ }^{17}$ for large databases on knee replacement in a cross-sectional population. ${ }^{18}$

For the purpose of our analysis we considered the questions in the Oxford knee score which related to pain and those which related to function separately (Table I). Scores for the five questions on pain were added together as were those for the seven on function. In order to allow a meaningful comparison between the total scores for pain and function, the scores were standardised and expressed as scores ranging between 0 and 1 . The standardised scores were calculated as the difference between the actual score and the lowest possible score divided by the difference between the highest and lowest possible scores. For example, a total pain score of 18 corresponded to a standardised total pain score of $65 \%$ as follows:

$$
\text { standardised total pain score }=\frac{18-5}{25-5}=0.65
$$

The assessment of satisfaction with the TKR was performed by asking patients the question 'Are you satisfied with your knee replacement'? with 'Yes', 'No' and 'Not sure' as possible answers.

Statistical analysis. Multivariable logistic regression was performed in an attempt to investigate which factors influenced whether patients were satisfied or not. For the purpose of this analysis, patients were divided into groups who had answered 'Yes', 'No' and 'Not sure', respectively to the satisfaction question. The regression coefficients were transformed into odds ratios, which can be considered as means of relative risks. An odds ratio of less than 1 indicates that patients in a given category were 
Table II. Comparison of the data from the National Joint Registry database ${ }^{9}$ for those patients who completed questionnaires and for those who did not by number and percentage

\begin{tabular}{|c|c|c|c|c|}
\hline & Not sent/ineligible & Returned & Not returned & Total \\
\hline Number & 14291 & 8231 & 1186 & 23708 \\
\hline Mean age (range) in years & 70.92 (26 to 96 ) & 70.82 (27 to 98 ) & 68.70 (25 to 92 ) & 70.68 ( 25 to 98 ) \\
\hline \multicolumn{5}{|l|}{ Age in years $(\%)$} \\
\hline$<65$ & $1258(8.8)$ & $2034(24.7)$ & $414(34.9)$ & $3706(15.6)$ \\
\hline 65 to 70 & $828(5.8)$ & $1534(18.6)$ & $209(17.6)$ & $2571(10.8)$ \\
\hline 70 to 80 & $1978(13.8)$ & $3465(42.1)$ & $393(33.1)$ & $5836(24.6)$ \\
\hline$>80$ & $799(5.6)$ & $1198(14.6)$ & $170(14.3)$ & $2167(9.1)$ \\
\hline Unknown & $9428(66.0)$ & $0(0)$ & $0(0)$ & $9428(39.8)$ \\
\hline \multicolumn{5}{|l|}{ Gender (\%) } \\
\hline Male & $2119(14.8)$ & 3557 (43.2) & $504(42.5)$ & $6180(26.1)$ \\
\hline Female & $2750(56.5)$ & $4671(56.8)$ & $681(57.4)$ & $8102(34.2)$ \\
\hline Unspecified & $9422(65.9)$ & $3(0.04)$ & $1(0.1)$ & 9426 (39.8) \\
\hline \multicolumn{5}{|l|}{ Hospital type (\%) } \\
\hline Not selected & $1136(7.9)$ & $191(2.3)$ & $31(2.6)$ & $1358(5.7)$ \\
\hline Independent & 2941 (20.6) & $1599(19.4)$ & $197(16.6)$ & 4737 (20.0) \\
\hline NHS & $10214(71.5)$ & $6441(78.3)$ & $958(80.8)$ & $17613(74.3)$ \\
\hline \multicolumn{5}{|l|}{ Type of prosthesis (\%) } \\
\hline Cemented & $11609(81.2)$ & $6917(84.0)$ & $993(83.4)$ & 19519 (82.3) \\
\hline Uncemented & $1166(8.2)$ & $547(6.6)$ & $81(6.8)$ & $1794(7.6)$ \\
\hline Hybrid & $141(1.0)$ & $113(1.4)$ & $14(1.2)$ & $268(1.1)$ \\
\hline Unicondylar & $1221(8.5)$ & $584(7.1)$ & $87(7.3)$ & $1892(8.0)$ \\
\hline Patellofemoral & $154(1.1)$ & $70(0.9)$ & $11(0.9)$ & $235(1.0)$ \\
\hline \multicolumn{5}{|c|}{ American Society of Anesthesiologists grade ${ }^{14}(\%)$} \\
\hline 1, fit and healthy & 4790 (33.5) & $2338(28.4)$ & $313(26.4)$ & 7441 (31.4) \\
\hline 2, mild disease & 8081 (56.6) & $4982(60.5)$ & $702(59.2)$ & $13765(58.1)$ \\
\hline 3 , incapacitating disease & $1390(9.7)$ & $902(11.0)$ & $165(13.9)$ & 2457 (10.3) \\
\hline 4, life-threatening disease & $30(0.2)$ & $9(0.1)$ & $6(0.5)$ & $45(0.2)$ \\
\hline \multicolumn{5}{|l|}{ Side (\%) } \\
\hline Left & 6763 (47.3) & $3912(47.5)$ & $550(46.4)$ & 11225 (47.3) \\
\hline Right & $7528(52.7)$ & $4319(52.5)$ & $636(53.6)$ & $12483(52.7)$ \\
\hline \multicolumn{5}{|l|}{ Lead surgeon (\%) } \\
\hline Consultant & $11155(78.1)$ & $6291(76.4)$ & $912(76.9)$ & $18358(77.4)$ \\
\hline $\begin{array}{l}\text { Associate specialist/staff grade/clinical } \\
\text { assistant }\end{array}$ & $884(6.2)$ & $695(8.4)$ & $97(8.2)$ & $1676(7.1)$ \\
\hline SPR/SHO/Other* & $2252(15.8)$ & $1245(15.1)$ & $177(14.9)$ & $3674(15.5)$ \\
\hline \multicolumn{5}{|l|}{ Indication for surgery (\%) } \\
\hline Osteoarthritis & $13813(96.7)$ & 7924 (96.3) & 1107 (93.3) & $22844(96.4)$ \\
\hline Other & 478 (3.3) & $307(3.7)$ & $79(6.7)$ & $864(3.6)$ \\
\hline \multicolumn{5}{|l|}{ Incision (\%) } \\
\hline Lateral & $132(0.9)$ & $45(0.6)$ & $5(10.4)$ & $182(0.8)$ \\
\hline Medial & $1868(13.1)$ & $1150(14.0)$ & $155(13.1)$ & $3173(13.4)$ \\
\hline Midline & $12291(86.0)$ & $7036(85.5)$ & $1026(86.5)$ & $20353(85.9)$ \\
\hline \multicolumn{5}{|l|}{ Tourniquet used (\%) } \\
\hline Yes & 13258 (92.8) & 7760 (94.3) & 1118 (94.3) & 22136 (93.4) \\
\hline No & $1033(7.2)$ & $471(5.7)$ & $68(5.7)$ & $1572(6.6)$ \\
\hline \multicolumn{5}{|l|}{ Fat pad removed (\%) } \\
\hline No & $1730(12.1)$ & $1315(16.0)$ & $185(15.6)$ & $3230(13.6)$ \\
\hline \multicolumn{5}{|l|}{ Yes } \\
\hline Fully & $3859(27.0)$ & $2285(27.8)$ & $327(27.6)$ & 6471 (27.3) \\
\hline Partially & $8702(60.9)$ & 4631 (56.3) & $674(56.8)$ & $14007 \quad(59.1)$ \\
\hline
\end{tabular}




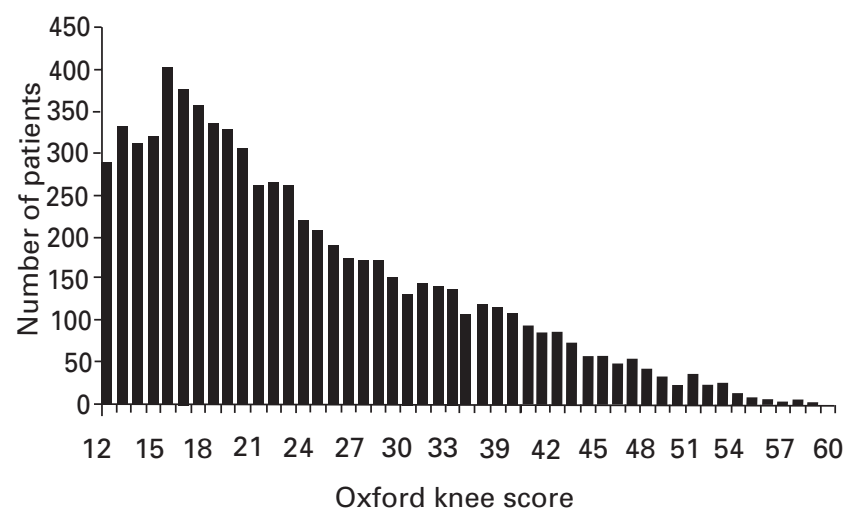

Fig. 1

Distribution of Oxford knee scores in the 7230 patients for whom it could be calculated.

less likely to be satisfied with their TKR than those in the baseline category. A p-value $\leq 0.05$ was considered to indicate statistical significance.

\section{Results}

Of the 10000 questionnaires sent out, 9935 were linked to data in the National Joint Registry database. Of these, we excluded 412 because they had been sent to patients who had undergone a revision procedure, 80 because they had been sent to patients who had bilateral procedure, and 26 because they had been sent to patients who had already received a questionnaire for an earlier operation or another joint. As a result, we considered 9417 questionnaires which had been sent to patients who had undergone a primary unilateral TKR. Of these, $8231(87.4 \%)$ were returned and $1186(12.6 \%)$ were not.

A comparison of the characteristics of the patients according to whether they received a questionnaire and whether they returned it is shown in Table II. For each of the three groups (questionnaire sent and returned, questionnaire sent but not returned, no questionnaire sent) there were only small differences in the clinical, surgical and demographic data. The patients who were sent a questionnaire were more often treated in the NHS.
The mean Oxford knee score could be calculated for 7230 of the 8231 patients $(87.8 \%)$ who returned questionnaires. The questionnaires of 1001 patients $(12.2 \%)$ had a missing answer to at least one of the questions. The mean Oxford Knee score was 25.0 (12 to 60; Fig. 1). Overall, only 291 of $7230(4.0 \%)$ patients had a score of 12 (the lowest possible score) and 331 of $7230(4.6 \%)$ had a score of 13 . Thus, 622 of $7230(8.6 \%)$ patients reported no or hardly any problems with their TKR.

The most commonly mentioned severe problems, with responses to individual questions rated as 4 or 5 , related to kneeling (4344 of $7619,57 \%$ of patients) persistent pain (1583 of $8010,19.8 \%$ ), pain on walking (1319 of 7926 , $16.6 \%$ ), and shopping (1273 of $8019,16.0 \%)$. Patients scored best with responses rated as 1 or 2 for questions related to the feeling of the knee having given way (7172 of $8076,88.8 \%$ ) the ability to wash and dry themselves (6682 of $8027,83.2 \%$ ), a limp (6339 of $7973,79.5 \%$ ), and pain on standing up from a chair after a meal (6245 of 7994, $78.1 \%)$.

The questions on satisfaction with the TKR were completed by 8095 patients (98.3\%). Overall, $81.8 \%$ (6625 of 8095 ) were satisfied, $11.2 \%$ (904 of 8095 ) were unsure and $7.0 \%$ (566 of 8095 ) were not satisfied. The distribution of the Oxford knee score varied according to patient satisfaction. The mean Oxford knee score was 22.0 (12 to 59) in satisfied patients, 35.2 (15 to 60 ) in those who were unsure and 41.7 (13 to 59 ) in the unsatisfied patients (multivariate regression modelling, $\mathrm{p}<0.001)$.

Significant differences were also seen in the pain and function scores (Table III). The mean standardised pain score was 0.19 ( 0 to 1 ) in those who were satisfied and 0.63 $(0$ to 1$)$ in those who were unsatisfied (multivariate regression modelling, $\mathrm{p}<0.001)$ and $0.48(0$ to 1$)$ in those who were unsure (multivariate regression modelling, $\mathrm{p}<0.001$ ). The mean standardised function score was 0.22 (0 to 1$)$ in those who were satisfied, 0.61 ( 0 to 1 ) in those who were unsatisfied, and 0.49 ( 0 to 1 ) in those who were unsure (multivariate regression modelling, $\mathrm{p}<0.001$ ). The pain and function scores were strongly correlated (Pearson's correlation coefficient $(\mathrm{r})=0.83)$.

We performed logistic regression modelling to establish the influence that pain and function, as well as relevant patient

Table III. Standardised pain and function scores dependent on satisfaction status

\begin{tabular}{|c|c|c|c|c|c|c|}
\hline \multirow[b]{3}{*}{ Score $^{*}$} & \multicolumn{6}{|c|}{ Satisfaction with total knee replacement } \\
\hline & \multicolumn{2}{|l|}{ Satisfied } & \multicolumn{2}{|c|}{ Unsatisfied } & \multicolumn{2}{|l|}{ Unsure } \\
\hline & Number & $\begin{array}{l}\text { Standardised score } \\
(95 \% \mathrm{Cl})^{\dagger}\end{array}$ & Number & $\begin{array}{l}\text { Standardised score } \\
(95 \% \mathrm{Cl})\end{array}$ & Number & $\begin{array}{l}\text { Standardised score } \\
(95 \% \mathrm{Cl})\end{array}$ \\
\hline Pain $(n=7761)$ & 6362 & $0.19(0.18$ to 0.19$)$ & 546 & $0.63(0.62$ to 0.65$)$ & 853 & $0.48(0.47$ to 0.49$)$ \\
\hline Function ( $\mathrm{n}=7347$ ) & 5963 & $0.22(0.22$ to 0.23$)$ & 535 & 0.61 (0.59 to 0.63$)$ & 849 & $0.49(0.47$ to 0.50$)$ \\
\hline
\end{tabular}


Table IV. Effect of pain and impaired function as well as patient and surgical characteristics on satisfaction with total knee replacement. An odds ratio of less than 1 indicates that patients in category were less likely to be satisfied with the knee replacement than the baseline group

\begin{tabular}{|c|c|c|c|c|}
\hline & Predictor & Odds ratio & $95 \% \mathrm{Cl}^{*}$ & p-value \\
\hline \multirow[t]{2}{*}{ Univariable results } & Pain elements of $\mathrm{OKS}^{\dagger}$ & 0.68 & 0.67 to 0.69 & $<0.001$ \\
\hline & Function elements of OKS & 0.76 & 0.75 to 0.77 & $<0.001$ \\
\hline \multirow[t]{2}{*}{ Multivariable results only including pain and impaired function } & Pain elements of OKS & 0.75 & 0.73 to 0.78 & $<0.001$ \\
\hline & Function elements of OKS & 0.90 & 0.88 to 0.92 & $<0.001$ \\
\hline \multirow{2}{*}{$\begin{array}{l}\text { Multivariable results including pain and impaired function as } \\
\text { well as patient and surgical characteristics }\end{array}$} & Pain elements of OKS & 0.77 & 0.74 to 0.79 & $<0.001$ \\
\hline & Function elements of OKS & 0.88 & 0.87 to 0.90 & $<0.001$ \\
\hline \multicolumn{5}{|l|}{ Age (yrs) } \\
\hline$<65$ & & $1.00^{\ddagger}$ & & \\
\hline 65 to 70 & & 0.99 & 0.78 to 1.25 & 0.91 \\
\hline 70 to 80 & & 1.23 & 1.01 to 1.49 & $<0.05$ \\
\hline$<80$ & & 1.06 & 0.82 to 1.36 & 0.67 \\
\hline \multicolumn{5}{|l|}{ Gender } \\
\hline Female & & $1.00^{\ddagger}$ & & \\
\hline Male & & 1.19 & 1.01 to 1.39 & $<0.05$ \\
\hline \multicolumn{5}{|l|}{ American Society of Anesthesiologists grade ${ }^{14}$} \\
\hline 1 & & $1.00^{\ddagger}$ & 0.92 to 1.33 & \\
\hline 2 & & 1.11 & 1.17 to 2.06 & 0.28 \\
\hline 3 & & 1.56 & 0.23 to 17.37 & 0.54 \\
\hline 4 & & 1.98 & & \\
\hline \multicolumn{5}{|l|}{ Procedure } \\
\hline Cemented & & $1.00^{\ddagger}$ & & \\
\hline Uncemented & & 0.94 & 0.69 to 1.27 & 0.68 \\
\hline Hybrid & & 0.70 & 0.38 to 1.29 & 0.25 \\
\hline Unicondylar & & 0.59 & 0.42 to 0.82 & 0.002 \\
\hline Patellofemoral & & 1.00 & 0.47 to 2.09 & 0.99 \\
\hline \multicolumn{5}{|l|}{ Lead grade } \\
\hline Associate specialist/staff grade/clinical assistant & & $1.00^{\ddagger}$ & & \\
\hline Consultant & & 1.17 & 0.89 to 1.54 & 0.25 \\
\hline SPR/SHO/other ${ }^{5}$ & & 1.02 & 0.74 to 1.40 & 0.92 \\
\hline \multicolumn{5}{|l|}{ Operation included } \\
\hline Other & & $1.00^{\ddagger}$ & & \\
\hline Osteoarthritis & & 0.58 & 0.36 to 0.92 & 0.02 \\
\hline \multicolumn{5}{|l|}{ Knee incision } \\
\hline Lateral & & $1.00^{\ddagger}$ & & \\
\hline Medial & & 1.47 & 0.51 to 4.27 & 0.48 \\
\hline Midline & & 1.54 & 0.54 to 4.39 & 0.80 \\
\hline \multicolumn{5}{|l|}{ Tourniquet used } \\
\hline No & & $1.00^{\ddagger}$ & & \\
\hline Yes & & 0.97 & 0.70 to 1.34 & 0.84 \\
\hline \multicolumn{5}{|l|}{ Fat pad removed } \\
\hline No & & $1.00^{\ddagger}$ & & \\
\hline Yes (fully) & & 1.00 & 0.78 to 1.30 & 0.98 \\
\hline Yes (partially) & & 0.99 & 0.79 to 1.24 & 0.92 \\
\hline
\end{tabular}

* 95\% Cl, 95\% confidence interval

† OKS, Oxford knee score

$\ddagger$ baseline values

$\S \mathrm{SPR}$, specialist registrar; SHO, senior house officer

and surgical characteristics, had on satisfaction. Table IV shows the univariable and multivariable results. The univariable analyses demonstrated that a patient with the highest possible total pain score ( 1 on the standardised scale or 25 points on the Oxford knee score scale) was 0.68 times as likely to be satisfied when compared with the lowest possible pain score $(0$ on the standardised scale or 5 points on the Oxford knee score). Similarly, a patient who had the highest 
Table V. Oxford knee score (OKS) and satisfaction related to complications

\begin{tabular}{|c|c|c|c|c|}
\hline \multirow[b]{2}{*}{ Question } & \multicolumn{2}{|l|}{ Yes } & \multicolumn{2}{|l|}{ No } \\
\hline & Mean OKS $(95 \% \mathrm{CI}) *$ & Satisfied (\%) & Mean OKS (95\% Cl) & Satisfied (\%) \\
\hline $\begin{array}{l}\text { Have you undergone another procedure on the operated } \\
\text { knee? }\end{array}$ & $31.35(30.35$ to 32.35$)$ & 59.6 & 24.48 (24.24 to 24.72$)$ & 83.7 \\
\hline Is another procedure planned? & 28.65 (28.04 to 29.26$)$ & 74.2 & 23.85 (23.61 to 24.11 ) & 84.7 \\
\hline $\begin{array}{l}\text { Have you experienced other problems with the operated } \\
\text { knee? }\end{array}$ & $30.64(30.15$ to 31.13$)$ & 57.9 & 21.67 (21.24 to 21.90$)$ & 94.9 \\
\hline
\end{tabular}

* $95 \% \mathrm{Cl}, 95 \%$ confidence interval

possible total function score was 0.76 times as likely to be satisfied when compared to a patient with the lowest possible function score.

When the effect of the total pain and function scores on patient satisfaction were considered simultaneously, we found that both odds ratios increased, compared with the univariable results. These adjusted results described the effect of one factor if the other remained constant. The increase was larger for function $(0.76$ to 0.90$)$ than for pain (0.68 to 0.75$)$. When we also included other patient characteristics, the odds ratio for pain changed to 0.77 and that for impaired function to 0.88 . Thus the effect of variations in pain on satisfaction were about twice as large as that of variations in function.

In addition to the influence of pain and function, we found that men were more often satisfied with their TKR than women (multivariate regression modelling, $\mathrm{p}<0.05$ ), and that patients with a diagnosis other than OA were more often satisfied than those with OA (multivariate regression modelling, $\mathrm{p}=0.02$ ) (Table IV). We also found some evidence to show that patients who had undergone unicondylar replacement were less likely to be satisfied than those who had cemented TKR (multivariate regression modelling, $\mathrm{p}=$ 0.002). Patients aged between 70 and 80 years were more likely to be satisfied compared with those aged less than 65 years (multivariate regression modelling, $\mathrm{p}<0.05$ ) as were patients who were ASA grade 3 when compared with those who were ASA 1 (multivariate regression modelling, $\mathrm{p}=$ 0.002). The grade of the lead surgeon (not authors), the site of the incision, the use of a tourniquet, and removal of the fat pad did not significantly influence satisfaction.

At the time of questioning, 609 patients $(7.4 \%)$ had undergone another procedure on the operated knee since their original surgery. In addition, 1476 patients $(17.9 \%)$ indicated that another procedure was planned and 2206 (26.8\%) had experienced other problems with the operated knee. The Oxford knee score and satisfaction rates related to the presence of complications are highlighted in Table V. Both were significantly better in patients who had not suffered complications $(\mathrm{p}<0.001)$.

\section{Discussion}

Our study had a high response rate of $87.4 \%$, indicating that patients who have undergone TKR are willing to participate in studies which investigate their experience. Of the 8095 patients questioned only $81.8 \%$ stated that they were satisfied with the outcome after their TKR, while $18.2 \%$ were not satisfied (unsatisfied or unsure). It is clearly disquieting that only $81.8 \%$ of patients were satisfied, and further investigation needs to be undertaken to establish whether this low level of satisfaction is related to poor surgical technique or a consequence of poor and inappropriate patient selection. It also raises questions as to the appropriate use of already scarce resources.

We found that at more than one year after TKR, patients had a mean Oxford knee score of 25.0. The score also varied significantly depending upon whether patients were satisfied or not. Patients who experienced more pain and functional impairment after TKR were less likely to be satisfied with the procedure. We found that a patient with the worst possible pain score was $23 \%$ less likely to be satisfied than one with the best possible score, while adjusting for a large number of other determinants of satisfaction. The corresponding figure for a similar variation in the functional impairment score was $12 \%$. These results are in agreement with our original hypothesis that pain is a stronger determinant than function.

Levels of satisfaction depend on the expectations held by patients. As with many other areas of health-care provision most patients have high expectations of the outcome after joint replacement. ${ }^{12,13,19,20}$ Even more noteworthy in this context is that patients often have higher expectations of relief from pain when compared with improvements in function. ${ }^{11,13}$ As a result the stronger impact of pain on levels of satisfaction than that of functional impairment may occur as a result of differences in patient expectation.

While pain was a stronger determinant of satisfaction, both factors were found to influence satisfaction significantly. This highlights the fact that priorities differ between individual patients. While one patient may accept residual pain, another might not, but instead they might tolerate a degree of functional limitation. This emphasises the importance of spending time and care pre-operatively addressing the expectations of each individual patient.

Using these data we were also able to demonstrate an association between satisfaction and the gender and underlying diagnosis of the patient. There was also some 
evidence that the type of prosthesis, age and ASA grade may influence satisfaction. However, care must be taken not to over-interpret these results. While our analysis has suggested an association, further investigation and statistical analysis are required to clarify to what extent each of these factors is a predictor of satisfaction.

The National Joint Registry contained the names and addresses of only $20 \%$ of the patients who had undergone a TKR in England and Wales during the period of study. ${ }^{21}$ This may have led to a selective inclusion of patients from centres with better facilities to support audit and clinical governance and potentially better quality of care. However, it is unlikely that this selective inclusion influenced the relationship between outcomes such as pain, functional impairment and satisfaction, since there was no obvious mechanism which could explain this influence.

A second limitation was that the National Joint Registry did not collect information on pain and function immediately before surgery. This is important since there is considerable evidence to show that a patient's pre-operative baseline level of pain and function is the single best predictor of pain and function after joint replacement. ${ }^{22}$ It was therefore impossible for us to investigate to what extent the observed effects of pain and function on satisfaction, at least one year after surgery, were linked to a patient's preoperative condition. Again, this is important since it is likely that satisfaction depends not so much on the post-operative level of pain and function, but on the changes in pain and functional impairment experienced by the patient after surgery.

There is also debate as to how satisfaction can be measured and to what extent it can be used as a method of assessing quality of care. ${ }^{23}$ Most patient surveys find a high level of satisfaction, which may cast some doubt on the validity of this as a measurement of the degree to which patients were satisfied with the care they had received. ${ }^{24}$ For example, it is known that closed questions which ask directly about levels of satisfaction produce answers that are more likely to be positive than open-ended questions. ${ }^{25}$ However, there is strong convergence between the results of the Oxford knee score and the level of satisfaction. Patients who indicated that they were satisfied with their TKR had scores which were considerably lower than those of patients who were unsure or unsatisfied.

Many experts in psychometrics may consider that our approach to the assessment of pain and function, carried out by breaking down the Oxford knee score into two components, as methodological heresy. One of their most important arguments is that the questionnaire has been developed with the objective that the included questions measure a single underlying concept. It is therefore no surprise that we found the total pain and function scores to be highly correlated. It is important to remain cautious when interpreting the regression coefficients (i.e. the odds ratio) of two highly correlated determinants. ${ }^{26}$ However, we feel that our approach is justified for an initial analysis since the breakdown into questions on pain and those on function is immediately obvious and has therefore strong face validity. Moreover, the precision of the regression coefficients for pain and impaired function was high despite this correlation because of the large number of patients included in the study.

A number of authors have previously reported satisfaction after TKR. The Swedish Arthroplasty Registry ${ }^{7}$ found that $81 \%$ of the 25000 patients who had had TKR were satisfied with the outcome of their surgery, $8 \%$ were not satisfied and $11 \%$ undecided. Other smaller studies have found similar results. ${ }^{5,6,8}$

Despite the abundance of studies examining the effect of operative- and prosthesis-related factors on the outcome of joint replacement, only a relatively small number have used satisfaction and patient-based scores as outcome measures. Consequently, little is known about the determinants of outcome after joint replacement other than the rate of revision and radiological failure.

A study by Anderson et al, ${ }^{5}$ which examined satisfaction in 74 patients with TKR over the age of 75 years, reported an association between decreased function and increased pain scores measured post-operatively using the WOMAC and SF-36 scores, and patient dissatisfaction. They also found satisfaction to be correlated with better pain scores on the WOMAC and SF-36. ${ }^{5}$ This study was, however, performed using a small number of patients from a more elderly sedentary population. In their analysis there was no association between satisfaction and age, gender, diagnosis or the presence of comorbidities.

Overall, there is little reported evidence relating to the impact of patient and surgical factors on patient-reported outcomes and even less about their influence on satisfaction. This has implications for decision-making when considering patients for joint replacement.

Our study has shown the feasibility of measuring patientreported outcomes and satisfaction on a national scale. Given that the alleviation of pain and improvement of function are the primary indications for joint replacement, the monitoring of such outcomes should be an integral part of any system of evaluation of the quality of joint replacement.

Our data represent a true reflection of the expected Oxford knee score and rate of satisfaction at one year after TKR. These results could be used as a national benchmark against which the results of individual providers can be compared.

Our study has shown an association between a number of clinical and surgical characteristics and patient satisfaction. This must be taken into account when analysing outcomes between centres since the case-mix from different institutions will vary, and it is especially important when looking at differences between NHS and private hospitals.

Also, surgeons could use information on the level of patient satisfaction when counselling patients about the prognosis of TKR. This would allow patients to be fully 
involved in the decision as to whether to have surgery as well as to give properly informed consent. Moreover, this information will help patients to formulate more realistic expectations about the outcome of the surgery which in itself may improve overall levels of satisfaction.

Lastly, our findings should guide research and development. New surgical techniques and innovative designs of prostheses may contribute to further reduction in pain after TKR which could have a major impact on patient satisfaction.

The authors acknowledge the National Joint Registry database and the National Joint registry Steering Committee for the use of the data.

No benefits in any form have been received or will be received from a commercial party related directly or indirectly to the subject of this article.

\section{References}

1. Rothwell PM, McDowell Z, Wong CK, Dorman PJ. Doctors and patients don't agree: cross sectional study of patient's and doctor's perceptions and assessment of disability in multiple sclerosis. BMJ 1997;314:1580-3.

2. Janse AJ, Gemke RJ, Uiterwaal CS, et al. Quality of life: patients and doctors don't always agree: a meta analysis. J Clin Epidemiol 2004;57:653-61.

3. Bullens PH, Van Loon CJ, De Waal Malefijit MC, Laan RF, Veth RP. Patient satisfaction after total knee arthroplasty: a comparison between subjective and objective outcome assessments. J Arthroplasty 2001;16:740-7.

4. Jones CA, Beaupre LA, Johnston DWC, Suarez-Almazor ME. Total joint arthroplasties: current concepts of patient outcomes after surgery. Clin Geriatr Med 2005;21:527-41.

5. Anderson JG, Wixson RL, Tsai D, Stulberg SD, Chang RW. Functional outcome and patient satisfaction in total knee patients over the age of 75. J Arthroplasty 1996;11:831-40.

6. Hawker G, Wright J, Coyte P, et al. Health-related quality of life after knee replacement. J Bone Joint Surg [Am] 1998;80-A:163-73.

7. Robertsson O, Dunbar M, Pehrsson T, Knutson K, Lidgren L. Patient satisfaction after knee arthroplasty: a report on 27,372 knees operated on between 1981 and 1995 in Sweden. Acta Orthop Scand 2000;71:262-7.

8. Heck DA, Robinson RL, Patridge CM, Lubitz RM, Freund DA. Patient outcomes after knee replacement. Clin Orthop 1998;356:93-110.
9. No authors listed. National Joint Registry for England and Wales: Summary Report the 2nd Annual Report. September 2005. http://www. njrcentre.org.uk (date last accessed 5 April 2007).

10. Dawson J, Fitzpatrick R, Murray D, Carr A. Questionnaire on the perception of patients about total knee replacement. J Bone Joint Surg [Br] 1998;80-B:63-9.

11. Mancuso CA, Salvati EA, Johanson NA, Peterson MGE, Charlson ME. Patient's expectations and satisfaction with total hip arthroplasty. J Arthroplasty 1997;12:387-96.

12. Eisler T, Svensson 0, Tengstrom A, Elmstedt E. Patients expectation and satisfaction in revision total hip arthroplasty. J Arthroplasty 2002;17:457-62.

13. Mahomed NH, Liang MH, Cook EF, et al. The importance of patient expectations in predicting functional outcomes after total joint arthroplasty. J Rheumatology 2002;29:1273-9

14. No authors listed. American Society of Anesthesiologists Relative Value Guide. ASA Publications, 2007.

15. Garratt AM, Brealey S, Gillespie WJ. Patient assessed health instruments for the knee: a structured review. Rheumatology 2004;43:1414-23.

16. Davies AP. Rating systems for total knee replacement. Knee 2002;9:261-6.

17. No authors listed. WOMAC ${ }^{T M}$ osteoarthritis index health status measurements for osteoarthritis. http://www.womac.org/ (date last accessed 3 July 2007).

18. Dunbar MJ, Robertsson 0, Ryd L, Lidgren L. Appropriate questionnaires for knee arthroplasty: results of a survey of 3600 patients from the Swedish knee Arthroplasty Registry. J Bone Joint Surg [Br] 2001;83-B:339-44.

19. McGuigan FX, Hozack WJ, Moriarty L, Eng K, Rothman RH. Predicting qualityof-life outcomes following total joint arthroplasty: limitations of the SF-36 Health Status Questionnaire. J Arthroplasty 1995;10:742-7.

20. March LM, Cross MJ, Lapsley H, et al. Outcomes after hip or knee replacement surgery for osteoarthritis: a prospective cohort study comparing patients quality of life before and after surgery with age related population norms. Med $J$ Aust 1999;171:235-8.

21. No authors listed. National Joint Registry for England and Wales: 1st Annual Report. September 2004. http://www.njrcentre.org.uk (date last accessed 5 April 2007).

22. Fortin PR, Clarke AE, Joseph $\mathrm{L}$, et al. Outcomes of total hip and knee replacement: preoperative functional status predicts outcomes at six months after surgery. Arthritis Rheum 1999;42:1722-8.

23. Aspinal F, Addington-Hall J, Higginson IJ. Using satisfaction to measure the quality of palliative care: a review of the literature. J Adv Nurs 2003;42:324-39.

24. Williams B. Patient satisfaction: a valid concept? Soc Sci Med 1994;38:509-16.

25. Carr-Hill RA. The measurement of patient satisfaction. J Public Health Med 1992;14:236-49

26. Bland M. An introduction to medical statistics. Third ed. Oxford: Oxford Medical Publications, 2000 